\title{
PSYCHIATRIC TESTIMONY IN PROBATE PROCEEDINGS
}

\author{
Harold S. HuLberT*
}

\section{INTRODUCTION}

Probate judges and other trial judges who have heard will contests, and appellate judges and supreme court judges who have reviewed such suits tell us two things: one is that psychiatric testimony or interpretation of the mental status and competency of the testator is more necessary in will contests than is generally recognized; the other is that having a psychiatric witness in court is not an unmixed blessing.

To turn to the first of these observations, there are some judges who have come to believe that there should and must be expert neuropsychiatric testimony in all cases where there is lay evidence, needing interpretation, as to the testator's mental incompetence. How this may best be achieved will require a generation of study and experimental application, and will require statutory enactments as well as growth in common law through broad decisions. Its evolution must be toward the expeditious, simple, and economical; the courts and courtrooms are so busy that simplicity and economy of time are veritable essentials. Courts are conducting a business of settling differences practically; practicability has eclipsed the abstract ideal of true and perfect justice in all its ramifications.

In essence, the psychiatrist needs much more truth in evidence presented for his interpretation.

The experts have both capabilities and limitations. The layman recognizes that not only is the psychiatrist the best informed in the nature of normal and of abnormal human nature, of mental abilities and of mental disabilities, of brain function and of brain disease, but he also recognizes that because the psychiatrist is accustomed to draw reliable conclusions from few data-e.g. spinal fluid cells as counted, unequal pupils and absent knee jerks, different types of memory disorder, inequality of the two sides of the face or of the reflexes of the two sides of the body, or from a confused mind or even a mind in stupor-that if the psychiatrist as expert witness is furnished a sampling of data of the functions of the mind of a deceased testator he is able to

- M.D., 19r4, University of Michigan. Fellow, American Psychiatric Association. Consulting psychiatrist, Chicago, and of the Gary, Indiana, public schools. Formerly member of the faculty of the College of Medicine of the University of Illinois. Associate Editor, lournal of the American Institute of Criminal Law and Criminology. 
make a reliable diagnosis which will be of valid and valuable help to the court and jury in a will contest.

Although no analogy is perfect, the comparison most commonly used is with a paleontologist, who can reconstruct an estimate of an animal, even prehistoric, if given a few typical bones such as skull, hip bone, a vertebra or two, maybe a rib and a bone or two of an extremity. Of course he could do better, much better, in reconstruction and estimate if given the entire skeleton or most of it. But if given sorne miscellaneous bones of the creature under study mingled with some other bones of other animals, say, of a strayed and bogged cow and part of an ossified, petrified paw of a turtle, he could not make a reconstruction which had the marks of verisimilitude. So with a psychiatrist as an expert witness in a will contest. $\mathrm{He}$ can in almost every case evolve a true and correct opinion from even fragmentary evidence, if those fragments are true and not false. But he is handicapped in a unique way, in that he is denied the right which the jury enjoys as one of its rights, namely, the right to reject the inconsistent as false. He rarely can evolve a true diagnostic opinion when he is offered fragments which are a bad mixture of truth, half-truth, and of false and even wilfully misleading evidence.

The expert looks to the judge as the authority on truth. What the judge permits he accepts as truth. He knows that the lawyers are partisans and combatants, that they do not combine to present all the truth but that each presents just certain truths or certain aspects of the truth. He neither approves nor disapproves of their efforts, for their technique is not his. He wants the word factory to turn out U. S. P. truth, and how it is done is not his affair. He looks to the judge to put on the stamp of approval, just as he looks for the label "Accepted, American Medical Association" on the bottles whose contents he uses in private practice. He does not care how the finished product is presented, in pills or liquids, in direct questions or in hypothetical questions, so long as he knows it is all true and verified and no extraneous matter is included.

In making the second point-that having a psychiatric expert witness in court is not an unmixed blessing-the judges explain that, though he may clarify the main situation, yet, as a by-product of his language and cumbersome psychiatric definitions and because of his demands and the modus operandi of handling him, there is created a constellation of lesser, complicated problems. No one has asked the psychiatrist his opinion how two sets of lawyers and one judge and one jury of assorted minds complicate the psychiatry of interpreting the mind of a deceased testator.

It may be safely concluded that the use, misuse, and limitations imposed on psychiatric interpretation and opinion are more generally unsatisfactory than is generally realized.

Nevertheless, in those will contests where the competency of the testator is a disputed point, or the testator's susceptibility to undue influence is in issue, the aid of a psychiatrist, used strictly within the legal rules designed for lay witnesses, is the 
best method evolved to date. I maintain that the present system is a good system and works out so that truth and justice predominate in over $5^{\circ}$ per cent of the cases where a psychiatric witness is used in will contests. "Over 50 per cent" leaves room for improvement. This is not scolding nor fault finding: it is an observation to be taken for what it is worth. The "rooms" for improvement include the statutes, common law and decisions of higher courts, the rules of court procedure, the judge, the two attorneys, the jury, the witnesses, and the non-testifying interested parties, as well as the expert witnesses. Each person in the courtroom has a hard job, faces many obstacles, and is bound to slur somewhat. All travel toward the same goal or destination, but by different roads. Hence there are apparently irreconcilable differences en route.

\section{The Human Factor}

Law writers and others of the bench and bar seem almost apologetic in discussing this topic of the application of psychiatry in court. There is no need for any lawyer to have an inferiority complex attitude toward the inability of the law in action to make proper use of that vital and great domain of human knowledge technically known as psychiatric knowledge of human nature. On the contrary, the law itself and legal practice earn new laurels as complicated cases come to trial and are adjudicated; unfortunately those laurels are not bestowed, because of the erroneous philosophy that "virtue is its own reward" and only error is news deserving comment. The law and law-in-action are admirable. They also are incomplete, therefore imperfect.

Psychiatry and psychiatrists under court rules are not at fault. No branch of medicine has made as great advances since $r 900$ as has psychiatry! No branch of medicine has as many real sick to attend every day as have the psychiatrists. Yet psychiatry, it must be admitted, does not do well in court. That is partly because psychiatric knowledge is incomplete, and largely because the 80 per cent of psychiatric knowledge which is non-technical and which might be understood by any openminded, intelligent man, if explained to him, has heretofore been too cloistered. It has not been "retailed to the consumer" or inculcated in the minds of men generally, including men who may appear in court in some rôle, e.g., judge, attorney, juryman, etc.

The reason the technical part of a will contest is not appreciated and treated with dignity or presented or handled well is the same reason that there are will contests, namely, the human factor. Many witnesses are liars or deliberately tell half truths only, many lawyers try to exclude the truth or part of the truth, many persons involved in the will contests are cheats, and many judges do not ascertain the whole truth but for one reason or another (satisfactory to themselves) exclude it in part. That last statement needs immediate explanation: many judges follow rules whereby they are obliged to exclude part of the truth. Other judges pre-judge, then drowse. Jurymen too. First impressionists! Their receptivity is poor. The contesting law- 
yers admittedly pre-judge but do not drowse. Witnesses too. A courtroom during a will contest is, unconsciously, a psychiatric clinic, too bereft of excellence, and certainly not an example of a unanimous quest for "the truth, the whole truth, and nothing but the truth." Yet that is the unconscious motto of every psychiatrist, more than it is of any man of any other discipline.

The main fault, however, lies in the laymen who testify or who knew of the testator yet do not testify.

Hidden witnesses and excluded witnesses are not confined to criminal trials. In will contests, of course, there are many simple people who knew the testator but who do not know how to talk on the stand: they draw inferences instead of telling facts. While on the witness stand, if they are put on at all, they are treated harshly, abruptly ordered-rudely, I'd call it-and not helped. Gold is where you find it; with patience, skill, and proper handling gold may be extracted from low grade ore. Much of value in evidence may be gleaned from persons who are not facile of speech or who are not alert in apperception. Trial court judges who lack skill and patience do poorly here, and do not control the lawyer of the opposing side. A judge should assist the stumbling, elderly witnesses so often encountered in will contests. Often attorneys are reluctant to put some witnesses on the stand, fearing that they may do poorly and ramble rather than answer. I maintain that the judge should, like an inquiring magistrate, hunt up such witnesses and from them draw out those facts which would help to clarify the vague concept the court and jury have of the testator.

Where a witness recounts conversations of the testator, his testimony should be subjected to great scrutiny, for the witness and "his side" may be vastly interested in the outcome of the contest, but where he recalls habits, customs, appearances, and things which others who knew the testator could describe, then his evidence is more credible. In other words, there is a great deal of secondary evidence which might be sought and presented, under the rules of evidence, which would be useful if patiently elicited.

Under the human factor, it must not be overlooked that there are sometimes some experts who are wilful liars, and others who through devotion to the cause of one party are as lopsided as any other paranoids. Of these, anon. Theoretically the psychiatrist is not interested in the outcome of the case. In practice often a trial attorney regards the psychiatrist whom he puts on the stand as a salesman, really as another lawyer, as one hired to support his case as far as his medical ethics and personal conscience will permit him. Combinations of such lawyers and experts do not wear well and not only mire themselves in time and with repetition but are mired in the eyes of the public. Of course an expert, especially where there are opposing experts, may not be believed by the jury, no matter what he says or refrains from saying, for credibility is not highly correlated to his knowledge or to truth. Therefore the psychiatrist really does not invade the province of the jury, for, though 
he gives a direct opinion, the jury decides if that opinion is right or is to be rejected in discharging its duty of establishing the fact that the testator was or was not competent. Nevertheless, the more evidence there is offered to psychiatrists, the closer together are their opinions, if these are not biased.

\section{INADEQUACY OF THE EVIDENCE}

It is almost axiomatic that in will contests the evidence is but fragmentary, and is necessarily small because of the rules of evidence evolved to exclude what probably would be irrelevant. It is so much the more important that all available truth be elicited.

Two reasonable methods come to mind. One is to have all the factual evidence of both sides put in before either side presents its psychiatric expert testimony. Or, in other words, the experts should appear in chief, but only after the lay witnesses of both sides have testified.

The other method has been described by Stephens and Hulbert in the Illinois Law Review for November, 1930, $\mathbf{1}$ in a conjoint paper entitled "Probate Psychiatry," in which a rather detailed description was offered of.a procedure of having a psychiatrist examine the testator fully, psychiatrically, the day the will was executed, and of having the psychiatrist be one of the subscribing witnesses and thus eligible to testify later if the will was contested, ${ }^{2}$ and, as Probate Judge Henry Horner suggested, to have the psychiatrist file his data and notes in his books in the regular order of his business so that if he too died before the will was contested the data and notes without opinion could be read in extenso to a living psychiatric witness for his opinion. This has been done by some wealthy testators who have already been through a few battles of the campaign well known as "a family fight"; but knowledge of the existence of these data and notes has to date aborted any tendency to attack wills so supported on grounds of incompetency or of susceptibility to undue influence, or of forgery.

To probate a will while the testator lives, as occasionally has been proposed, ${ }^{3}$ is one thing, and has considerable merit. To examine.psychiatrically the testator when he executes his will, or executes the last codicil, is another matter, and has its own distinctive merits, it is believed.

\footnotetext{
${ }^{2}$ Stephens, Probate Psychiatry-Examination of Testamentary Capacity by Psychiatrist as a Subscribing Witness (1930) 25 IlL. L. Rev. 276; Hulbert, Probate Psychiatry-A Neuro-Psychiatric Examination of Testator from the Psychiatric Viewpoint, id. at 288.

2 The subscribing witness must and should take every means necessary to satisfy himself as to the mental competency of the testator. See Jones v. Collins, 94 Md. 403, 51 Atl. 398 (rg02): "The subscribing witness is presumed to investigate the testator's mentality" and In re Miller's Will, 3 Boyce (Del.) 477,85 Atl. 803 (1912): "The court instructs the jury that the value of the opinion of a subscribing witness, like that of other witnesses, depends upon the opportunity the witness had to observe and judge the testator's mental condition and capacity at the time the will was executed, and upon his use of such opportunity."

"For proposals for ante mortem probate of wills, sec Report of Special Committee on Uniform Act to Establish Wills beforo Death of Testator, Proc. Nat. Conf. Comm. on Uniform State LAws for 1932, p. 463; Cavers, Ante Mortem Probate: An Essay in Preventive Law (r934) I Univ. of CHt. L. Rev. 440; Kutscher, Living Probate (1935) 2 I A. B. A. J. 427.
} 
To prevent murder to make impossible a probable or threatened change in the will, and to prevent isolation on the one hand or undue influence on the other, there is merit in the proposition that when a will is drawn by an attorney (a) there should be present an attorney of some other firm of attorneys and also a psychiatrist, and (b) the will be filed privately with the attorney as an officer of the court and not be filed publicly, as some of these proposals contemplate, where interested, embittered, or solicitous relatives and others may see it while the testator lives. The whole question of ante mortem probate needs legislative study, enactment and trial, but ad interim there already are methods a testator can use to insure that his last testament will be executed as he desires.

\section{More Power to the Judge}

In order that psychiatric interpretation may be of truly great value, more truth must be elicited before the data are propounded to the psychiatrist for his interpretation and opinion. The most practical way to do that is to grant more power to the judge. At once it is realized that the decentralists will object to endowing judges with more power than they already have. For a moment let us consider their "cons" and later the "pros."

Contra: Judges have lots of power now, but they do not use it with enough application. Power should not be vested in any man unless there be arrangements for appeal and yet higher appeal. Judges are too human, hence frail. Judges are too removed from contact with ordinary men and their needs and necessary reactions in life (e.g., an appellate judge who never drove an automobile passing on cases of men driving hastily to work and not stopping before each track of a multiple railroad crossing). Voters (e.g., labor) hate appointed judges, though they be fair, and want responsive, young, "ungrooved" judges. A judge who does try to "try the case before him" is unpopular with the lawyers, but at least they know what to do because they know where he stands. Half the litigants and their friends leave a lawsuit hating a judge, unless he has been aloof and let the lawyers try the case without interference unless and until called upon to pass on some question of law. Judges of trial courts in more and more states (here in the old Northwest territory, the region known to this author) already have the power to comment on witnesses and on the evidence, but are fearful of using that power lest it impair their chances of re-election.

Pro: People trust judges, and judges have demonstrated as a body (with some or many exceptions, it is true) that they are worthy of the trust of the people. On appeals, at least three judges sit together; on appeals to the highest appellate courts, five, seven and nine sit together. The world has known of at least five types of prisoners, all having been judged: civil, including criminals who have been tried for breaking the civil law, political prisoners, religious prisoners, military prisoners 
and personal prisoners. ${ }^{4}$ In the United States we now only have type one, i.e., civil (criminal) prisoners. We rarely have type four, war or court martial under martial law prisoners, and in those cases we deeply prefer to have them tried or passed upon by elected civil judges. Ancient and modern history abroad indicates that there is a tendency by ruling minorities to have the other types, especially political and religious prisoners. What is "just around the corner for us in the United States" does not worry common Americans as long as we have trust in empowered and powerful judges.

Yes, we demand a strong judiciary. In will contests, too, the judge should be empowered and required to interrogate lay witnesses and get the full truth, not half truths. He should be able to summon witnesses. He should punish liars with contempt of court, or inaugurate contempt of court or other proceedings for perjury without delaying the progress of the case on trial. He should remove false witnesses from the stand on his own motion without waiting to hear an objection. It would be better to exclude obvious lies from the evidence and thus exclude falsities from the hypothetical question than to admit them and also admit evidence from the other side to refute them: the latter method is rather practical for jury consideration, but the inconsistencies make the evidence impractical as premises for a hypothetical question. He also should punish with contempt of court quack psychiatrists and paranoid biased "experts." In our language he should be a surgeon as well as be a physician. Fundamentally, he is to control the human factor, and secondarily control court procedure.

A judge at his best neither drowses nor is affected by political affiliations. Some observers might say a judge is never at his best, for he is too busy. Yet, if encouraged, even a most modest judge will react on a high plane. A judge's average best may be made a very high average.

A powerful judge can interpret abstruse psychiatry. The psychiatrist, to do his best, needs a judge with such power actively used.

\section{The Hypothetical Question}

Its use in practice and its quirks are well known. It is usefull But it is raw as presented. To the jurymen, the hypothetical question is "bad" enough, but, to the jurymen, the hearing of the discussions of it, objections to this and that part of it, its modifications, its restatement by the opposing side, all tend to make ludicrous the issue, the court, the lawyers, the expert, and the parties litigant.

It is here recommended that the hypothetical question be discussed and settled in privacy just as instructions to the jury are discussed and settled in chambers. There is, however, mistrust and suspicion of what may be transpiring in chambers. The Michigan practice on this point is practically ideal: the hypothetical question is debated and polished in open court, jury and witnesses and experts all excluded.

'This classification is from a study, unpublished, on the psychology of different types of prisoners, while imprisoned and upon release or rescue. 
If the hypothetical question is long, in courtesy and following the mode of preparing instructions, it is typed and submitted in advance to the court and to opposing counsel. The opposing side of course may, for cross examination, prepare, submit, and, when, in chambers or with jury and witnesses excluded, the question or questions have been polished and rendered acceptable, use several hypothetical questions embracing various theories of defense.

But the present practice of misusing the hypothetical question as restatement of the case to re-impress the jury is bad strategy, though good tactics; bad strategy in that it is so unfair and confusing and degrading that it does not clarify the issue nor help achieve justice. Degrading in that the jurymen conclude that a lawyer who cannot prepare an impeccable hypothetical question is "no good" and that the other critical attorney who himself cannot substitute an impeccable hypothetical question is "no good either," and a judge who cannot by force and leadership see that an impeccable hypothetical question is evolved must have "something the matter with him, too." However, a hypothetical question which meets the demands of both lawyers and which really suits an empowered judge may with efficacy be presented to the psychiatric expert witness. We do things better in our hospitals: relatives and friends and tensely waiting expectant fathers are not sitting in the obstetrical delivery room; we do our work in privacy, and then bring to those interested and waiting the end result of our handiwork. The courts, too, can do better than they do do: creating a hypothetical question should be done in private.

The psychiatrist has the right to demand of the law in action that what is presented to him be true and be accepted by both sides as satisfactory. Or, he has the right to demand that he be allowed the right to select the truth and not "swallow it whole." That is the essence of this proposal. Restated, either the judge should see to it that the hypothetical question contains only the truth from the witnesses and from the evidence, or the expert witness must see to it that from the hypothetical question he considers only what appears to him to be true. The inconsistencies, as stated, are or may be absurd. Referring to a recent case in which I served as expert, five witnesses stated that the testator weighed 160 to I80 pounds, and one witness testified that the testator weighed xoo pounds (before he died), one attending physician stated that his blood pressure was 200 (m.m. mercury systolic) and the hospital record was that his blood pressure was 100. On cross examination, counsel asked: "Assume further, Doctor, that the hypothetical man weighed 160 to 180 pounds, and assume he weighed roo pounds, and assume that his blood pressure was 200, and assume it was roo ... have you an opinion ... etc?" The question was intended to be absurd and to make the expert and his answer silly. I interrupted and asked the judge what I was to assume. He replied, "You must assume it all, all as equally true, and delete nothing of the hypothetical question from your mind," I asked him if he could do that, and he replied, "No, but you must." How much better if the 
judge had ironed out the phraseology of the hypothetical question and had seen to it that it was a fair presentation.

Or better still, since the question is hypothetical but the subject is actual, why not so say? Say, "There is some evidence tending to prove so . . . and so ... and so ..." not "Assume thus . . ., . . and that. . .." That is what appellate courts say: "There is evidence tending to prove so ... and so. ..." So in the question at the trial, say: "Five witnesses testified that when he was in fair health before his stroke the testator weighed 160 to $x 80$ pounds, and one witness testified that before the testator died he weighed roo pounds; one attending physician testified that Mr...... had a blood pressure of 200 in 1929 , and in the hospital in 1930 the records in evidence showed that his blood pressure was roo."

Would both lawyers say it that way? No. Could the judge insist it be stated fairly and helpfully? Yes. Should the judge do so? The expert demands that the judge see to it that the data be presented truly, fairly and impartially.

An extreme case of absurdity in hypothetical question is quoted in an editorial in the Journal of Criminal Law and Criminology for September-October, 1933.

(I933) 24 J. Crns. L. \& Crrmin. 517. The examination of the witness proceeded as follows:

Q. Now, Doctor, are you familiar with the philosophy of heterogeneous and homogeneous evolution as applied to the science of medicine? A. No.

Q. Did you ever hear of it? A. No.

Q. Do you know whether or not the internal organs reason deductively or inductively? A. That is quack medicine.

Q. That is quack medicine? A. Yes, sir.

Q. Will you answer the question, do you know, or don't you know?

A. The answer is no, $I$ don't know.

Q. You do not know then the philosophy of heterogeneous and homogeneous evolution as applied to the science of medicine? A. No, no.

Q. Assume this, Doctor. Is it true from a scientific basis that one might suffer a twenty-five per cent injury, we will say, by way of identification of the first joint of the thumb, or any finger on their hand, and yet the incapacity might be increased to seventy-five per cent or more, if you would take into consideration the heterogeneous and homogeneous evolution as applied to that particular injury, or to the science of medicine, due to the fact that the particular organs contained within the human body have certain and definite functions when they exist and stand alone as particular organs, and when they work or operate homogeneously, that is similarly and are thrown together for the purpose of keeping body and soul together, have you an opinion whether or no this is scientifically true,-

Atty. S: That is certainly a honey.

Mr. P: Pardon me, I had not finished.

The Witness: The question is if you lose the use of your thumb, an you think within seventy-five per cent of normal?

Mr. P: No, that is not the question at all. Read the question. That is not in it. My question has nothing to do with the mentality as yet. Do not try to make it ridiculous, Doctor.

The Judge: Read the question.

(Last question read.)

Mr. S: You are making it ridiculous. If anybody in Christendom can tell what that question is, I would like to hear their explanation.

The Judge: Let him finish it.

Mr. P: Have you an opinion whether or not this is scientifically true, taking into consideration the entire membrane, in conjunction with the particular joint as mentioned in this question?

Mr. S: Now, have you finished the question?

Mr. P: Yes.

Mr. S: I object to it as absolutely unintelligible.

The Judge: "Objection sustained."

As the Judge said later about that question, "It certainly is a peach." 
Under present procedure the judge could not exclude it until it had been propounded and until an objection to it had been raised. The psychiatric expert- witness can answer fairly several hypothetical questions based on different concepts or theories of the evidence, but he can not give the answer to a battle. Nor in dignity should he listen to the battle. The judge should assume responsibility here too. He can participate, and he "knows what it is all about."

\section{CoMmISSIONS OF ExPERTs?}

Dissatisfaction does exist in regard to the differences of opinions of psychiatrists testifying on opposite sides as expert witnesses. Often this dissatisfaction is deserved. There are, or, to be generous, let us say there were, some bad men among psychiatrists who testified often. Bad, not ignorant. Such an one said to me, "When I want to lean and win a case, suppose the patient was a Dementia Praecox and my lawyer did not want to have him proven insane, I'd examine him for General Paralysis. Then I'd tell the jury he did not have fixed pupils nor absent knee jerks nor tremors nor memory defect, etc. See? Not a sign nor symptom of [that] insanity!" Only an alert, incisive, and acting judge could handle such a rascal. The human factor again. He's dead, and is where bad psychiatrists go. I believe such cases are rare among the objectively trained younger psychiatrists, and are not to be found among the best one or two hundred of our older psychiatrists.

Another cause of dissatisfaction is a carry-over from criminal trials. It was once generally though ignorantly believed that any doctor who testified "for" a criminal and "agin the gove'ment" was a consort of criminals, a criminal "doc" himself, a morphine addict, an abortionist, etc., whereas a doctor who testified against the criminal was sanctified, was of course telling the truth or if he wasn't he was an upright man helping to hang the wicked. Yet no one would ask a court stenographer to do her best to hang the wicked by deleting from the records what the defense witnesses said. Nor do we want a judge with one deaf ear. Nor should we want a doctor who saw only through the eyes of a politician, temporarily prosecuting attorney. Some experts are still too susceptible, and others are damned because the side who sought their counsel is the unpopular side, be it in criminal trials or in civil proceedings such as will contests. Public sentiment will take attitudes and newspapers will continue to use young reporters who contribute unwittingly to the immaturity of public opinion. Only judges may be expected to have the old-age philosophy of accepting human frailty.

The third cause of dissatisfaction is because, in private practice, doctors agree in public. In public! In their own circles they may, and if equals, usually do disagree with each other. But the consensus of opinion is presented to the public, to the relatives for example, as a unanimous opinion. That works best for the welfare of the sick.

So in public, as in a trial, when doctors do disagree, it comes as an unwelcome 
shock. No one likes it, judges, lawyers, jurymen, parties litigant or interested, nor the public. Nor do the doctors as a group nor the doctors called into the law suit.

The trend right now is not toward the time tried method of letting the court and jury decide disputed points, but to have a commission. The prototype is, naturally, the old method in medicine, of calling in a consultant. Note the word "a"a consultant. If we called in nine consultants, they might divide five to four.

So, let us have a commission. Let the judge or appointed state officials appoint a neutral doctor. Politics or statecraft will determine who he is to be, and, we may say sarcastically, being appointed by the judge or the state house crowd will make him, pro tem at least, a super-doctor and a super-man. Anyway, he will be as neutral as the judge is who is elected and to be re-elected or is appointed by someone who was elected and to be re-elected-maybe.

Such a train of thought may or may not have merit in will contests.

Let us see how it does work out in two other types of law suits. In workmen's compensation and negligence cases, because of the great risk of malingering or of exaggeration or compensation neurosis, the human factor may cause the plaintiff to react to the tendency or impulse to be abnormal; consequently it would be well to have present at any medical examination by the doctor of each side a doctor representing the state board for workmen's compensation, to act as a referee as to medical findings, but without opinion. In will contests there is no parallel. The testator does not think of malingering, nor is a contest of his will often contemplated by a testator; hence no referee of medical facts can be had.

Let us see how it works out in criminal cases. No man can prove that he himself is insane. Therefore three psychiatric examinations are in order, but each independent of the others. One by the prosecution's psychiatrists, and their medical findings, e.g., that the defendant does not have paresis, should be reported only to the prosecution and may be used by the prosecution. One by the defense, and the medical findings, e.g., that the defendant has epilepsy and epileptic equivalents, should be reported only to the defense attorneys to be a basis for their theory of the defense. The third by the court's examiner and advisor, to safeguard the court in protecting the state in the future. All objective data of each of the two sides, Wassermann, spinal fluid findings, x-rays, etc., are to be furnished to the court's examiner. $\mathrm{He}$ is to help the judge. His views on the question of probation or minimum or maximum sentence may be consulted.

In will contests there is no parallel. The testator was an amateur testator, not an habitual criminal-I mean testator-nor a consorter with other testators. Nor does the testator contemplate malingering or evasion.

There is neither room nor need for a court-appointed expert or commission in will contests. An amicus curiae, an interpreter to the judge lest he make mistakes, is always in order. Of course. But not a super-expert on facts for the jury. The jury are the super-experts on facts. 
From what has been said and indicated above, there appears to be a very real need of separating the false from the true. No better method of achieving this end is known than that of cross-examining experts, provided the experts had first been given all the truth available and which might be elicited. Cross-examination under such circumstances, and also examination by an empowered judge, would be welcomed by every high minded, competent psychiatrist. Cross-examination is the only antidote for sanctimonious paranoid "experts" who rely on prestige and the invocation of moral issues to give them impressiveness or increase their impressiveness. Cross-examination is better than any commission. The human factor must be made manifest and be differentiated from the scientific factors.

\section{ConcLusron}

I. The human factor is the greatest complication in will contests, much greater than the complications of technical psychiatry. There is more perjury and half truths told by lay witnesses in will contests than in any other kind of law suit.

2. As a basis for psychiatric interpretation and opinion, more truth, more evidence is needed. An actively participating judge may bring out more truth, more relevant evidence. More truth. More power to the judge.

3. When the courts do better, as they can in their province and by natural extension of existing legal machinery, the psychiatrists can do better in the province where psychiatry and the law-in-action overlap. With improved court procedure, psychiatry will rise to the challenge. Both law and medicine are intelligent disciplines, and that their liaison may be more satisfactory each should improve itself and not try to improve each other.

4. Psychiatry does, and always will do, as well as permitted, considering the legal circumstances, considering the mixture of truth, fractions of truth and misleading untruth, and considering the human factor.

5. Either the judge must see to it that the data be presented truly, fairly and impartially in the hypothetical question propounded to the psychiatric expert witness for his opinion and interpretation, or else the judge should elicit all the possible secondary evidence and the expert should be allowed considerable latitude in rejecting inconsistencies and in weighting evidence which is confirmed by other evidence. The jury retains the right to accept the expert's opinion as right and true or to reject it as false and untrue.

6. The hypothetical question should be prepared in chambers or in court with jury and witnesses excluded before being propounded to the expert psychiatric witness.

7. More intelligent and more thorough cross-examinations of lay witnesses as well as of expert witnesses are indicated and needed in matters as highly involved as psychiatric interpretations of a deceased testator. 
8. In will contests a court-appointed commission of experts is not a remedy, for the jury is the expert on fact. An amicus curiae to advise the judge and to interpret psychiatric findings to him, but not to the jury, is in order.

9. Unanimity of opinion among experts is not to be expected.

Io. Psychiatric examination of the testator when he executes a will or codicil will settle in advance many issues which otherwise might be raised in the trial and poorly or incompletely handled. 